\title{
Effect of Aluminium Addition on the Magnetic Properties of a Semi-Processed Electrical Steel
}

\author{
Kleiner Marques Marra ${ }^{a}$, Livia Carneiro Marra ${ }^{b}$,Vicente Tadeu Lopes Buono ${ }^{c}$
}

\author{
${ }^{a}$ Department of Mechanical Engineering, Centro Universitário UNA, Belo Horizonte, MG, Brazil \\ ${ }^{b}$ Department of Chemical Engineering, Universidade Federal de São João Del Rei, Ouro Branco, MG, Brazil \\ ${ }^{c}$ Department of Metallurgical and Materials Engineering, Universidade Federal de Minas Gerais, \\ Belo Horizonte, MG, Brazil
}

Received: October 30, 2015; Revised: July 18, 2016; Accepted: August 11, 2016

\begin{abstract}
Aluminum is often added to electrical steels since this element causes improvement of the magnetic properties. However the addition of aluminum is usually limited to $0.30 \mathrm{wt} \%{ }^{1}$. Therefore, this work aimed at evaluating the influence of higher levels of aluminum in the magnetic properties of semiprocessed steels. To accomplish this, four types of steel were produced in laboratory with different aluminum contents $(0.10,0.30,0.60$ and $1.0 \mathrm{wt} \%)$. Carbon, manganese and silicon concentrations were kept constant. It was observed that an increased aluminum content caused reduction of the magnetic core loss, especially of the eddy current component. However, the magnetic permeability virtually wasn't influenced by aluminum concentration.
\end{abstract}

Keywords: magnetic core loss, magnetic permeability, aluminum addition, semi-processed electrical steel.

\section{Introduction}

Grain non-oriented (GNO) electrical steel is employed mainly to the cores of electric generators and motors. GNO steels are suitable for this application because of the small anisotropy of magnetic properties. Within this class of materials, there is the semi-processed electrical steel, which is usually supplied as cold rolled sheet and, in this condition, has inadequate magnetic properties ${ }^{2,3}$. These properties are enhanced through heat treatments carried out by the fabricators of motors and generators, commonly denominated decarburization treatment. This sort of treatment results in a reduction of the carbon content, as well as in a decrease in the residual stress level, the formation of a thin oxide layer on the sheet surface, and the occurrence of secondary recrystallization with an expressive grain growth and improvement of the crystallographic texture ${ }^{3}$.

Regarding the chemical composition, carbon, sulfur, nitrogen, and oxygen are commonly present in GNO steel in low concentration, and their presence is inherent to the steel production process. Such elements are very harmful to magnetic properties. Carbon forms iron carbides, which cause an increase in the hysteresis loss and a reduction in magnetic permeability ${ }^{4}$. Additionally, carbon in solid solution may precipitate owing to the warming of the generators and motors core, and this leads to the magnetic aging phenomenon ${ }^{4,5}$. Sulfur and nitrogen yield $\mathrm{MnS}$ and AlN particles in the metal matrix and, in turn, oxygen is present as oxide inclusions. All aforementioned second phase particles are injurious to the magnetic characteristics because they hamper the movement of the magnetic domains,

*e-mail: kleiner.marra@prof.una.br especially when they occur in diameters as small as tenths of micrometers ${ }^{6}$. If thinner, such particles play the role of inhibitors of grain growth during the steel decarburization treatment, yielding small grains and resulting in inadequate magnetic properties?

On the other hand, the controlled addition of certain elements which form substitutional solid solution with iron can promote the improvement of magnetic properties. Therefore, $\mathrm{Si}, \mathrm{Mn}, \mathrm{P}$ and $\mathrm{Al}$ are usually added to cause an increase in the electrical resistivity. However, the use of such elements should be made in a controlled manner, as, when in excess, they can reduce the saturation magnetic polarization.

Aluminum, in particular, besides increasing the electrical resistivity, also decreases the temperature range in which austenite exists (ferritizing effect) and, when in high concentrations, stabilizes and reduces the dissolution of the AlN precipitate, mainly during the steel hot rolling. The latter effect is important for weakening the formation of ND// $\{111\}$ texture ("gamma fiber"), which is not suitable for magnetic properties ${ }^{1,8,9}$.

Therefore, this study aimed at evaluating the effect of high levels of aluminum concentration on the magnetic properties of semi-processed steel.

\section{Experimental Procedure}

The pilot scale production of the semi-processed electrical steels was firstly carried out with the casting of four small ingots $(50 \mathrm{~kg})$ in a vacuum melting furnace. Different chemical compositions were obtained in accordance to aluminum content, as shown in Table 1. It can be noticed that all alloys display low levels of carbon, sulfur and nitrogen, 
Table 1: Chemical composition (\% mass).

\begin{tabular}{lccccccccc}
\hline Alloy & $\mathrm{CBD}(*)$ & $\mathrm{CAD}(* *)$ & $\mathrm{Mn}$ & $\mathrm{Si}$ & $\mathrm{N}$ & 0.0021 & 0.0095 \\
A1 & 0.0034 & 0.0009 & 0.53 & 0.95 & 0.97 & 0,0020 & 0.290 \\
A2 & 0.0044 & 0.0015 & 0.53 & 0.94 & 0,0017 & 0.0096 \\
A3 & $0, .0041$ & 0.0017 & 0.51 & 0.98 & 0,0013 & 0.950 \\
A4 & 0.0030 & $0, .0005$ & 0.54 & 0.0095 & \\
\hline
\end{tabular}

(*) CBD: carbon content before decarburization. (**) CAD: carbon content after decarburization.

and practically the same manganese and silicon contents. Aluminum was increased from A1 alloy (about $0.1 \mathrm{wt} \%$ ) to A4 alloy (about $1.0 \mathrm{wt} \%$ ).

The hot rolling was carried out in two stages: roughing and finishing. Firstly, the ingots were reheated in a muffle furnace and kept there at $1110^{\circ} \mathrm{C}$ for 180 minutes. They were then hot rolled in a laboratory rolling mill through a sequence of 11 reversible passes, and their thickness was reduced from $135 \mathrm{~mm}$ to $35 \mathrm{~mm}$. The materials were air cooled to room temperature, then heated again to $1100^{\circ} \mathrm{C}$ and kept at this temperature for 1.0 hour. Afterward, the second stage of hot rolling was conducted by targeting the finishing temperature at $850^{\circ} \mathrm{C}$, which resulted in a thickness of $7.0 \mathrm{~mm}$.

The hot coiling was simulated by putting the material inside a muffle furnace at $750^{\circ} \mathrm{C}$ for 1.0 hour, after which the furnace was turned off so as to cool the materials to room temperature.

Before undergoing cold rolling, the thickness was reduced from $7.0 \mathrm{~mm}$ to $2.2 \mathrm{~mm}$ by machining. After that, cold rolling was carried out in order to obtain a final thickness of 0.5 $\mathrm{mm}$, i.e. $77 \%$ thickness reduction. The operation was also conducted using a laboratory rolling mill.

To simulate bath annealing, cold rolled samples underwent a thermal cycle, which consisted of $17^{\circ} \mathrm{C} / \mathrm{h}$ heating rate, soaked at $660^{\circ} \mathrm{C}$ for $7.0 \mathrm{~h}$, and cooled at a rate of $12^{\circ} \mathrm{C} /$ hour.

After bath annealing, a typical skin pass rolling for semi-processed steels was used, i.e. $6 \%$ thickness reduction.

The decarburization treatment was executed in a muffle furnace, under natural atmosphere conditions and at a $120^{\circ} \mathrm{C} / \mathrm{h}$ heating rate, in a way that it soaked at $760^{\circ} \mathrm{C}$ for 2 hours and cooled at a rate of $90^{\circ} \mathrm{C} / \mathrm{h}$.

Samples of semi-processed electrical steels were evaluated via quantitative metallography (i.e. microstructural observation and average ferritic grain size measurement), determination of $\alpha / \gamma$ transformation temperature (Ac1 and Ac3), and assessment of crystallographic texture and magnetic properties (core magnetic loss and magnetic permeability at 1.5 Tesla and $60 \mathrm{~Hz}$ ).

$\mathrm{Ac}_{1}$ and $\mathrm{Ac}_{3}$ transformation temperatures were determined through analyses which were carried out in a DIL 805A/DBähr dilatometer.

Crystallographic texture has been evaluated by measuring $\{110\},\{200\}$ and $\{222\}$ direct pole figures using an X-ray - X Siemens diffractometer, D5000 model, under Mo K $\alpha 1$ radiation and by the Schulz back reflection method. From the direct pole figures was derived the ODF (orientation distribution function), and the following texture fibers were obtained in section equivalent to $\varphi_{2}$ at $45^{\circ}:(<110>/ / \mathrm{RD})$, $(<100>/ / \mathrm{ND}),(\{\mathrm{hkl}\}<001>)$, and $(<111>/ / \mathrm{ND})$.

Because of the small width of cold rolled samples, magnetic properties were measured only along the rolling direction with the use of an Epstein Frame coupled with a Brockhauss Messtechnik equipment, MPG 100 D model.

\section{Results and Discussion}

After the decarburization treatment, the carbon content was very low for all the alloys, below 18 ppm (Table 1).

Figure 1 shows the electric resistivity values for all steels, calculated according to the equation given by the ASTM A-98 712 Standard, which takes into account only aluminum and silicon contents. As expected, the increased aluminum content led to a steady rise of electrical resistivity.

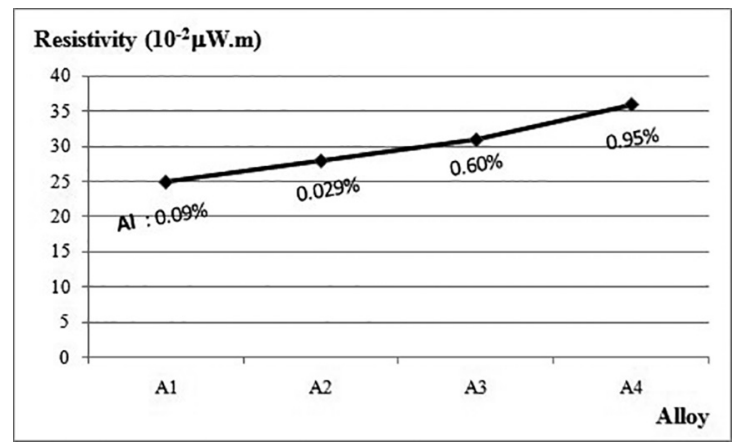

Figure 1: Electrical resistivity calculated by ASTM A 712-98 Standard.

The $\alpha / \gamma$ critical transformation temperatures, Ac1 and, Ac3, which indicate the conditions of the ferrite/austenite transformation, are shown in Table 2. The increase in aluminum caused an elevation of both aforementioned temperatures, since this element stabilizes the ferrite phase, similarly to silicon.

Table 2: $\alpha / \gamma$ transformation temperatures.

\begin{tabular}{lcc}
\hline Alloy & $\mathrm{AC} 1\left({ }^{\circ} \mathrm{C}\right)$ & $\mathrm{AC} 3\left({ }^{\circ} \mathrm{C}\right)$ \\
\hline $\mathrm{A} 1$ & 910 & 975 \\
$\mathrm{~A} 2$ & 960 & 1015 \\
$\mathrm{~A} 3$ & 1010 & 1110 \\
$\mathrm{~A} 4$ & $>1150$ & $>1150$ \\
\hline
\end{tabular}


Ferritic grain size progress during the material processing can be seen in Figure 2. After decarburization, there was full grain growth for all alloys (the average grain size was bigger than 90 $\mu \mathrm{m})$, and it is worth noting a tendency of grain size reduction with increasing aluminum content. This effect might be linked to the increase in the amount of precipitate (especially AIN) from A1 to A4 steel. Fine precipitates can hinder the kinetic of grain growth during decarburization treatment ${ }^{3,4}$. As hot rolled or annealed condition, the steel samples showed smaller grains without clear influence of aluminum concentration.

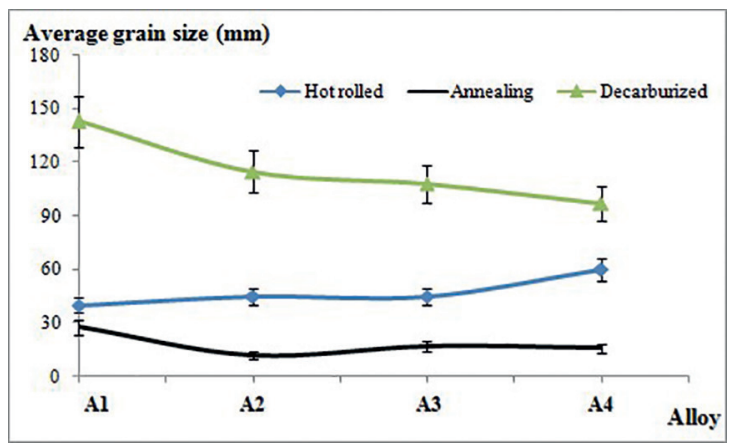

Figure 2: Grain size evolution during steels fabrication.
Regarding crystallographic texture, Figure 3 shows the main texture fibers for electrical steels, i.e. three suitable components for magnetic properties: alfa fiber $(<110>/ / \mathrm{RD})$, cubic fiber $(<100>/ / \mathrm{ND})$ and RD' fiber $(\{\mathrm{hkl}\}<001>)$, and an unsuitable component: gamma fiber $(<111>/ / \mathrm{ND})^{8}$. The evaluation of the area under the "fiber curves" by mathematical numeric integration, according to the Simpson's rule ${ }^{10}$, can be seen in Figure 4. The results can hence be interpreted as indicators of the incidence of each type of fiber. As shown in Figure 4, the higher the aluminum content, the more attenuated all components, which resulted in a texture randomization.

As to the magnetic properties, Figure 5, there was a clear trend towards reduction in the magnetic core loss (at 1,5T and $60 \mathrm{~Hz}$ ) with the increase in the aluminum concentration. For a better analysis of this behavior, the core loss was separated in two parts: (i) the classic eddy-current component and (ii) the hysteresis component, using the Bertoti Method ${ }^{11}$. This method doesn't consider the anomalous component.

Figure 6 shows that increasing aluminum content considerably decreased the eddy-current component. Certainly, this was mainly due to increased electrical resistivity. However, Figure 7 presents the progress of the hysteresis component, and it can be observed that the aluminum content increase

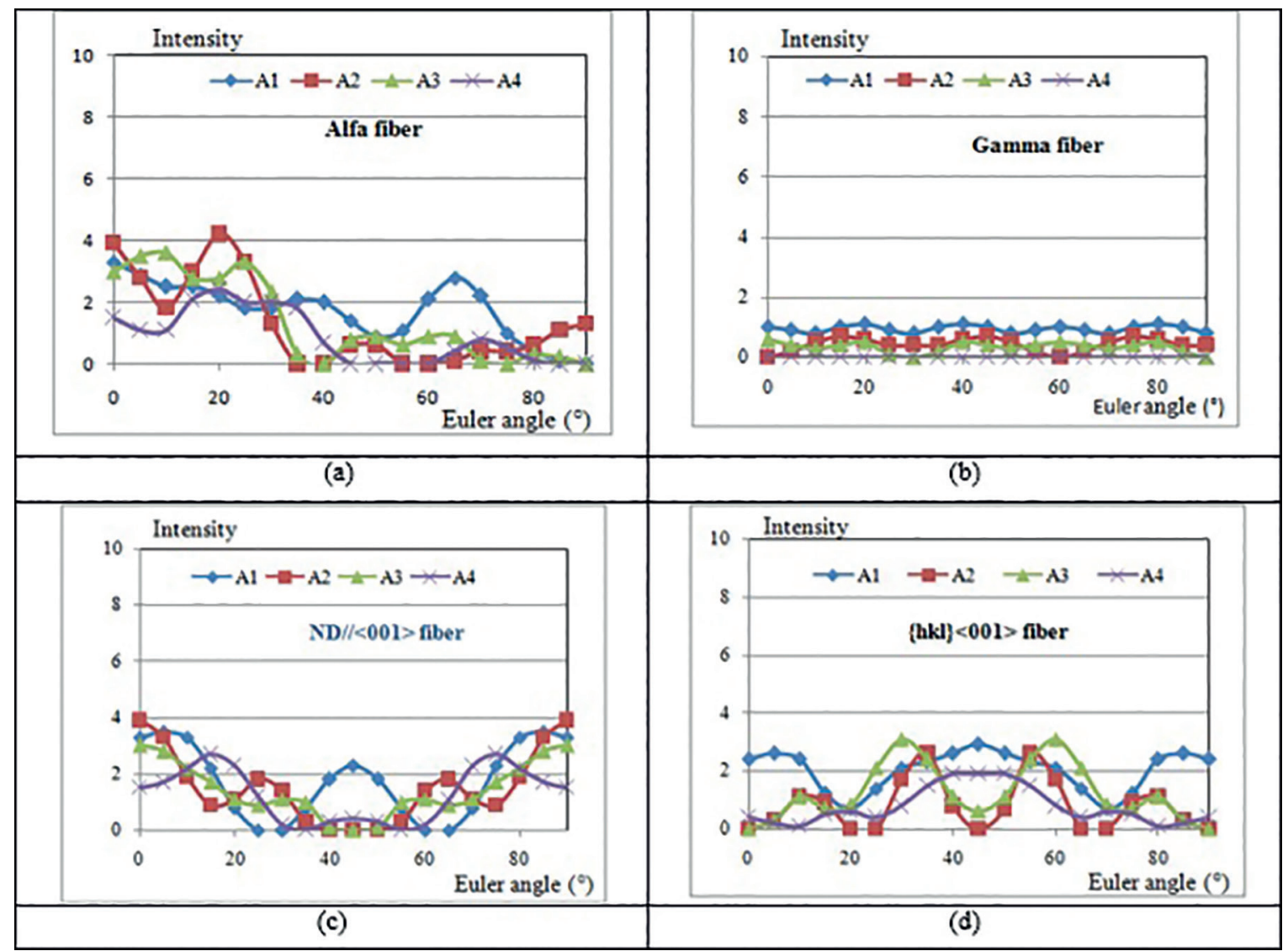

Figure 3: Fiber figures: (a) Alfa, (b) Gamma, (c) Cubic and (d) RD'. 


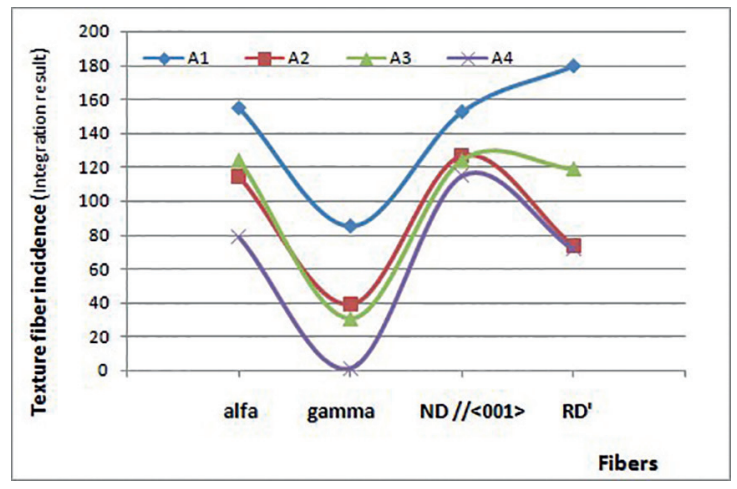

Figure 4: Incidence of each type of fiber.

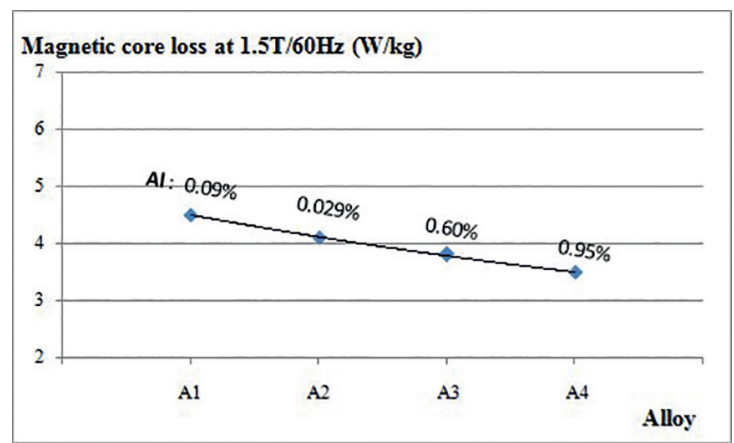

Figure 5: Variation of magnetic core loss in function of Al content.

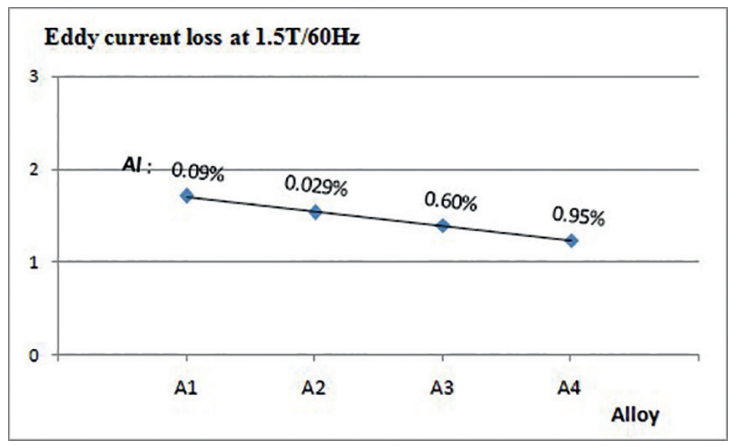

Figure 6: Variation of eddy-current loss as function $\mathrm{Al}$ content.

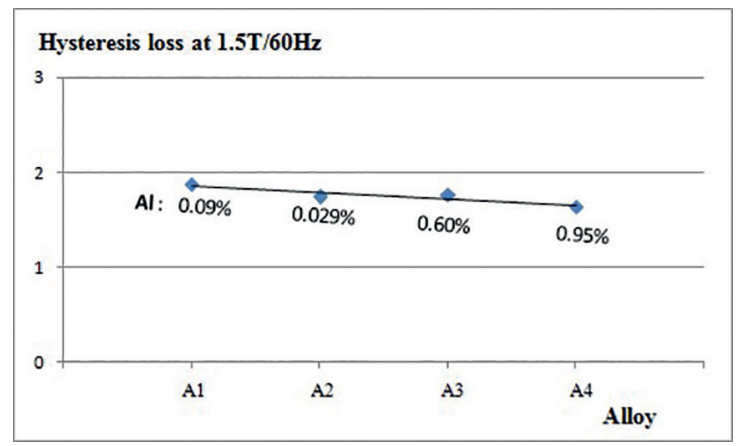

Figure 7: Variation of hysteresis loss as function $\mathrm{Al}$ content. caused a discreet reduction on this magnetic loss component, despite the texture randomization and probable increased presence of second phase particles in the metallic matrix $\mathrm{x}^{3,9,11}$.

Magnetic permeability (at $1,5 \mathrm{~T}$ and $60 \mathrm{~Hz}$ ), shown in Figure 8 , displayed no clear trend towards variation with the aluminum content and reached a plateau. The negligible effect of aluminum content on the magnetic permeability can be justified by two arguments: (i) this property is not strongly affected by precipitates under high induction values (like $1,5 \mathrm{~T}$ ), and (ii) other "suitable" components of crystallographic texture were possibly created after decarburization treatment, with the randomization process.

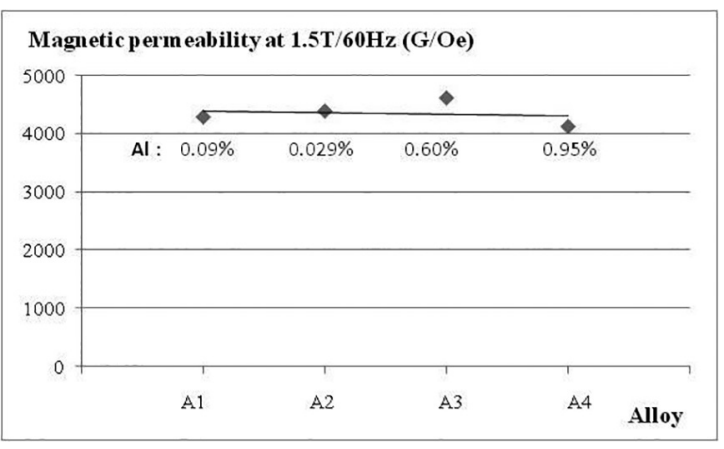

Figure 8: Variation of magnetic permeability in function of Al content.

\section{Conclusion}

The produced semi-processed electrical steels reached full ferritic grain growth after decarburization treatment.

With respect to electrical resistivity, the increase in the $\mathrm{Al}$ content promoted a steady rise of this property.

Concerning crystallographic texture, it was observed that the increase in aluminum content caused a strong attenuation of gamma fiber, alfa fiber, cubic fiber, and RD' fiber.

Regarding the magnetic properties, it was seen that the aluminum increased addition led to the reduction of the magnetic core loss and did not significantly change the magnetic permeability. The magnetic core loss variation might be justified by the effect of aluminum on the electrical resistivity. With respect to the magnetic permeability, the texture randomization and probable more intense presence of second phase particles caused by increased aluminum content did not have a strong negative effect on it.

Therefore, the alloy with higher concentrations of $\mathrm{Al}$, around $1 \%$, exhibited the best magnetic properties along the rolling direction, i.e. core loss around 3,5W/ $\mathrm{kg}(1.5 \mathrm{Tesla}$ and $60 \mathrm{~Hz})$ and permeability next to 4000 $\mathrm{G} / \mathrm{Oe}(1.5$ Tesla and $60 \mathrm{~Hz})$. 


\section{References}

1. Nakayama T., Honjou N. Effect of aluminum and nitrogen on the magnetic properties of non-oriented semi-processed electrical steel sheet. Journal of Magnetism and Magnetic Materials. 2000;213(1-2):87-94.

2. Barros J., Targhetta A., León O., Ros T., Schneider J., Houbaert Y. Effect of temper rolling on the texture formation and magnetic properties of non-oriented semi-processed electrical steel. Journal of Magnetism and Magnetic Materials.2007;316(2):e865-e867.

3. Marra K.M., Alvarenga E.A., Buono V.T.L. Decarburization kinetics during annealing of a semi-processed electrical Steel. ISIJ International.2004;44(3):618-622.

4. Marra K.M., Alvarenga E.A., Buono V.T.L. Magnetic aging anisotropy of a semi-processed non-oriented electrical steel. Materials Science and Engineering: A. 2005;390(1-2):423-426.

5. Sidor Y., Kovak F. Effect of heat treatment conditions on the internal and external oxidation processes in non-oriented electrical steels. Materials \& Design. 2005;26(4):297-304.
6. Michal G.M., Slane J.A. Carbide precipitation in electrical steels. JOM The Journal of The Minerals, Metals \& Materials Society (TMS). 1986;38(1):32-36.

7. Vanherpe L., Moelans N., Blanpain B., Vandewalle S. Pinning effect of spheroid second-phase particles on grain growth studied by three-dimensional phase-field simulations. Computational Materials Science. 2010;49(2):340-350.

8. Kestens L., Jacobs S. Texture control during the manufacturing of non-oriented electrical steels. Texture, Stress, and Microstructure. 2008; 2008:173083.

9. Park, J.T., Development of annealing texture in nonriented electrical steels. Doctoral Thesis, Department of Mining, Metals and Materials Engineering, McGill University, Montreal, Canada; 2002, 192p.

10. Davis P.J., Rabinowitz P. Methods of numerical integration. New York:Academic Press; 1984. 632p.

11. Bertotti G. General properties of power losses in soft ferromagnetic materials. IEEE Transactions on Magnetics. 1988;24(1):621-630. 